\title{
A CROSS-RATIO INEQUALITY FOR QUASICIRCLES
}

\author{
WANG Gendi, Chu Yuming AND Zhang XiAOHui
}

Abstract. In this note we give a geometric characteristic for quasicircles by making use of cross-ratios, which is analogous to quadruple points identity of circles.

Mathematics subject classification (2000): 30C62.

Key words and phrases: Quasicircles, cross-ratio, Möbius mappings.

\section{REFERENCES}

[1] M. VuORINEN, Conformal Geometry and Quasiregular Mappings, Lecture notes in Mathematics, Springer-Verlag, Berlin, 1988.

[2] J. CIEŚLIŃSKI, The cross ratio and Clifford algebras, Adv. Appl. Clifford Algebras, 7(1997), $133-139$.

[3] A. BLunCK, Cross-ratios in Moufang-Klingenberg planes, Geom. Dedicata, 43(1992), 93-107.

[4] I. KRA, On Teichmüller's theorem on the quasi-invariance of cross ratios, Israel J. Math., 30(1978), 152-158.

[5] O. LEHTO, Univalent Functions and Teichmüller Space, Springer-Verlag, New York, 1987.

[6] A. F. BEARdon, The Geometry of Discrete Group, Springer-Verlag, New York, 1983.

[7] Z. M. BALOGH, Hausdorff dimension distribution of quasiconformal mappings on the Heisenberg group, J. Anal. Math., 83(2001), 289-312.

[8] D. SULLIVAN, Quasiconformal homeomorphism and dynamics II: Structural stability implies hyperbolicity for Kleinian groups, Acta Math., 155(1985), 243-260.

[9] A. KORÁNYI, H. M. RIEMANN, Foundations for the theory of quasiconformal mappings on the Heisenberg group, Adv. Math., 111(1995), 1-87.

[10] L. V. AHLFORS, Quasiconformal reflection, Acta Math., 109(1963), 291-301.

[11] F. W. GEHRING, Uniform domain and the uniquitous quasidisk, Jber. Deutsch. Math.-Verein., 89(1987), 88-103.

[12] B. G. OsGOOD, Univalence criteria in multiply-connected domains, Trans. Amer. Math. Soc., 260(1980), 459-473.

[13] J. G. KRZYŻ, Quasicircles and harmonic measure, Ann. Acad. Sci. Fenn. Ser. A I Math., 12(1987), 19-24.

[14] Y. M. Chu, J. F. Cheng, Quasidisks and modulus monotone domains, Acta Math. Sinica, 39(1996), 556-560 (In Chinese).

[15] O. Lehto, K. I. VIRTANEN, Quasiconformal Mappings in the Plane, Springer-Verlag, New York, 1973.

[16] S. B. Agard, F. W. GeHring, Angles and quasiconformal mappings, Proc. London Math. Soc.,(3), 14a(1965), 1-21. 